\title{
Efficacy of Muscodor albus for the Control of Phytophthora Blight of Sweet Pepper and Butternut Squash
}

\author{
A. R. Camp, H. R. Dillard, and C. D. Smart, Department of Plant Pathology and Plant-Microbe Biology, Cornell \\ University, and New York State Agricultural Experiment Station, Geneva 14456
}

\begin{abstract}
Camp, A. R., Dillard, H. R., and Smart, C. D. 2008. Efficacy of Muscodor albus for the control of Phytophthora blight of sweet pepper and butternut squash. Plant Dis. 92:1488-1492.

The efficacy of Muscodor albus, a potential soil biofumigant, to control root and stem rot by Phytophthora capsici, was examined in a greenhouse study. P. capsici-infested potting mix was treated with three rates of M. albus, mefenoxam (Ridomil Gold EC, Syngenta Crop Protection, Inc.), or nothing. Seedlings of five sweet pepper cultivars and one butternut squash cultivar were transplanted into the treated potting mix. After 7 days, the plants were rated on a scale of 0 (healthy) to 5 (dead). The experiment was conducted three times and there was a significant interaction between pepper cultivar and soil treatment. Treatment with the highest rate of $M$. albus resulted in a slight but significant reduction in disease severity on Alliance, Aristotle, Paladin, and Revolution pepper compared with the pathogen-only control, while no significant decreases in disease severity were observed with butternut squash or the highly susceptible pepper cv. Red Knight. Of the four less-susceptible pepper cultivars, Paladin (the most tolerant cultivar) was the only one on which M. albus, as applied in this study, reduced disease severity to commercially acceptable levels.
\end{abstract}

Phytophthora capsici (Leonian) was first isolated from chili pepper (Capsicum annuum) in New Mexico in 1918 (12) and, since then, it has also been reported on sweet pepper, tomato, eggplant, and cucurbits (8), as well as snap bean (7) and lima bean (4). Cucurbit hosts are susceptible to root, crown, and fruit rots that result in either plant death or rotting of fruit before or after harvest, causing significant yield losses (8). Current control recommendations include cultural practices to reduce standing water in the field (8), tolerant cultivars $(5,8,9)$, and chemical fungicides and fumigants (8). In production regions around the country, isolates of $P$. capsici that are insensitive to the fungicide mefenoxam are becoming an increasing problem (8). Areas of Michigan have received exemptions to continue use of the fumigant methyl bromide in order to continue production of susceptible hosts in the presence of mefenoxam-insensitive isolates of $P$. capsici (8), but this is not a long-term sustainable solution to the problem. Some sweet pepper cultivars that are tolerant to $P$. capsici are available, but no resistance or tolerance is currently available for hot pepper, eggplant, tomato, or cucurbits (8).

Corresponding author: C. D. Smart

E-mail: CDS14@cornell.edu

Accepted for publication 27 June 2008.

doi:10.1094/PDIS-92-11-1488

(C) 2008 The American Phytopathological Society
The tropical endophytic fungus Muscodor albus was first isolated from a cinnamon tree (Cinnamomum zeylanicum) in Honduras (26). It produces a variety of volatile organic compounds that inhibit in vitro a number of fungal, oomycete, and bacterial species, including plant pathogens (26). Thus, it has been proposed that M. albus could have agricultural applications as a soil biofumigant to kill soilborne plant pathogens (including $P$. capsici; 26). Because $P$. capsici is not aerially dispersed (8), intentional cultural practices could be employed to prevent or at least delay the reintroduction of $P$. capsici into a field that had been fumigated with $M$. albus. Furthermore, because the production of long-lived oospores by $P$. capsici limits the effectiveness of crop rotation to control Phytophthora blight (8), the potential destruction of oospores by biofumigation with $M$. albus (although not yet demonstrated) would be especially useful to growers.

There have been a number of reports of the successful use of $M$. albus as a biofumigant. Several studies successfully used M. albus to control postharvest diseases of fruit, including gray mold (Botrytis cinerea) on grape (6); brown rot (Monilinia fructicola) on peach (20); blue mold (Penicillium expansum), gray mold (B. cinerea), and brown rot (M. fructicola) on apple (15); and green mold ( $P$. digitatum) and sour rot (Geotrichum citri-aurantii) on lemon (17). Stinson et al. reported that a rate of $2 \mathrm{~g}$ of Muscodor albus inoculum in $425 \mathrm{~g}$ of autoclaved and pathogen-infested soil significantly reduced disease severity on sugar beet caused by Rhizoctonia solani, Pythium ultimum, and Aphanomyces cochliodes, and on eggplant caused by Verticillium dahliae, compared with pathogen-only controls (25). In a field experiment, $M$. albus applied at 3.75 or 1.9 $\mathrm{g} /$ liter of soil controlled root and hypocotyl rots on radish caused by $R$. solani (2).

In addition, in a greenhouse study, Mercier and Manker (16) demonstrated that $M$. albus provided complete control of both damping-off of broccoli seedlings caused by $R$. solani and Phytophthora blight on a susceptible sweet pepper cultivar (California Wonder). There are no published studies using $M$. albus to control Phytophthora blight on cucurbits. Phytophthora capsici continues to be a significant problem for vegetable growers in New York State, and previous studies have indicated the potential for the successful control of $P$. capsici with $M$. albus; therefore, this study was initiated in order to test the efficacy of $M$. albus on additional cultivars and crops. The goals of this study were to (i) determine whether M. albus is effective as a biofumigant against Phytophthora blight on five sweet pepper cultivars and one butternut squash cultivar and (ii) determine whether efficacy of $M$. albus varies based on host tolerance of pepper cultivars.

\section{MATERIALS AND METHODS}

Plant materials. Five sweet pepper cultivars were used in this experiment: Alliance (Harris, Rochester, NY), Aristotle (Seminis Inc., St. Louis), Paladin (Syngenta Crop Protection, Inc., Greensboro, NC), Red Knight (Seminis Inc.), and Revolution (Harris). All cultivars were seeded into Cornell potting mix (composed of peat, perlite, and vermiculite in a $4: 1: 1$ ratio) and were germinated and grown in the greenhouse in 128-cell flats under natural light for 24 to 38 days before being transplanted into treated soil (described below). Additionally, Butternut squash (cv. Waltham; Stokes Seeds, Inc., Buffalo, NY) was seeded into Cornell potting mix in 50cell flats and germinated and grown under natural light in the greenhouse for 11 to 14 days prior to transplanting.

Preparation of $P$. capsici inoculum. The $P$. capsici isolate (NY 0664-01) used in this experiment was isolated from a pepper plant in New York in 2006 and is sensitive to mefenoxam. The isolate was cultured on 100-by-15-mm petri dishes of 
$15 \%$ V8 agar for 5 to 7 days (11). Equal areas of each agar plate colonized by $P$. capsici were cut into small cubes about 0.5 $\mathrm{cm}$ in diameter and the contents of one plate was used to inoculate 1 liter of V8vermiculite substrate ( 0.5 liter of $20 \%$ V8 broth and 1 liter of vermiculite) which had been mixed and sterilized in a 2-liter Erlenmeyer flask (19). The agar plugs of $P$. capsici were mixed into the substrate by gentle shaking and the inoculated flasks were incubated in the dark at room temperature for 10 to 12 days and shaken three times per week. Before inoculating soil, approximately $1 \mathrm{~g}$ of vermiculite was removed from each of the flasks and incubated on $15 \%$ V8 agar to confirm that $P$. capsici had colonized the substrate. Substrate without $P$. capsici was also made for use in noninoculated controls.

Soil inoculation and treatments. To make infested potting mix, 12 liters of $P$. capsici-inoculated V8-vermiculite substrate was thoroughly mixed with 36 liters of moistened Cornell potting mix to achieve a 1:4 ratio of vermiculite inoculum to potting mix, similar to the protocol used by Mercier and Manker (16). This P. capsici-inoculated potting mix was then divided into five portions (each containing about 9.5 liters) for treatment with different rates of M. albus. The M. albus used in this trial was obtained from AgraQuest, Inc. (Davis, CA) and had been grown on rye grain before being dried for storage. Three of the $P$. capsici-inoculated soil portions were treated with $M$. albus formulated on rye grain at a rate of $3.75,1.9$, or $0.55 \mathrm{~g} /$ liter of soil. The remaining two portions were left untreated for the $P$. capsici-only control and the mefenoxam $+P$. capsici control. After treatment, the potting mix in each portion was mixed thoroughly and used to fill 30 square plastic pots $(10.16 \mathrm{~cm})$ with approximately $300 \mathrm{~cm}^{3}$ of potting mix.

To produce potting mix for the nopathogen controls, uninoculated V8vermiculite substrate was mixed with Cornell potting mix in a 1:4 ratio, as above. The potting mix was divided into four portions for treatment with $M$. albus inoculum at the three rates described above plus one portion of soil left untreated. From each container, 30 pots were filled with approximately $300 \mathrm{~cm}^{3}$ of potting mix, as for the inoculated soil.

In total, there were nine soil treatments for each of the five pepper cultivars and one squash cultivar: $P$. capsici only, $P$. capsici + mefenoxam, P. capsici + M. albus at $3.75 \mathrm{~g} /$ liter, $P$. capsici $+M$. albus at $1.9 \mathrm{~g} / \mathrm{liter}$, P. capsici + M. albus at 0.55 g/liter, no $M$. albus + no $P$. capsici, only $M$. albus at $3.75 \mathrm{~g} /$ liter, only $M$. albus at 1.9 $\mathrm{g} /$ liter, and only M. albus at $0.55 \mathrm{~g} / \mathrm{liter}$. All pots from all treatments were covered with plastic and stored in the dark at 20 to $22^{\circ} \mathrm{C}$ for 7 days to enable the $M$. albus to grow and fumigate the soil (25).
Efficacy of $M$. albus to control $P$. capsici on sweet pepper. One week after the soil was inoculated, two pepper seedlings were transplanted into each pot. All seedlings were thoroughly watered prior to transplanting. Five replications of each treatment and cultivar combination were arranged in a randomized complete block design on greenhouse benches. The greenhouse was kept at approximately $24^{\circ} \mathrm{C}$ during the day and $20^{\circ} \mathrm{C}$ at night, with about $15 \mathrm{~h}$ of natural light. Approximately $100 \mathrm{ml}$ of water was added to each pot (from the top), except for those pots which were to be treated with mefenoxam. Pots treated with mefenoxam received $100 \mathrm{ml}$ each of a Ridomil Gold EC solution (Syngenta Crop Protection, Inc.) at a rate of 1.5 liters/ha. All pots were watered 2 to 3 days after transplanting with $150 \mathrm{ml}$ of water, gently poured onto the top of the pot to avoid splashing.

Each pot (containing two plants) was rated as a unit using a scale adapted from Silvar et al. (24): $0=$ both plants healthy; 1 $=$ less than or equal to $50 \%$ of total stem area with lesions or less than or equal to $50 \%$ of all leaves wilted or missing; $2=$ more than $50 \%$ of total stem area with lesions or more than $50 \%$ of all leaves wilted or missing; $3=$ less than or equal to $50 \%$ of total stem area having lesions and more than $50 \%$ of all leaves wilted or missing, or vice versa; $4=$ more than $50 \%$ of total stem area having lesions and more than $50 \%$ of leaves wilted or missing, but growing tip still upright and green; and $5=$ both plants dead. Plants were rated when the $P$. capsici-only control plants were dead ( 7 days after transplanting). The entire experiment was repeated three times; thus, with five replicates per experiment, there were 15 ratings for each treatmentcultivar combination.

Efficacy of $M$. albus to control $P$. capsici on butternut squash. In the butternut squash experiment, there were a total of nine soil treatments (as in the pepper experiment) but only one butternut squash cultivar. One week after the soil was inoculated, two squash seedlings were transplanted into each pot and pots were watered with either $100 \mathrm{ml}$ of water or $100 \mathrm{ml}$ of mefenoxam (Ridomil Gold EC at a rate of 1.5 liters/ha). Five replications of each treatment were arranged in a randomized complete block design on a greenhouse bench. The greenhouse was kept at approximately $24^{\circ} \mathrm{C}$ during the day and $20^{\circ} \mathrm{C}$ at night, with approximately $15 \mathrm{~h}$ of natural light. All pots were watered 2 to 3 days after transplanting with $150 \mathrm{ml}$ of water gently poured onto the top of the pot to avoid splashing. Each pot (containing two plants) was rated as a unit using the same scale described above. Plants were rated when the $P$. capsici-only control plants were dead ( 7 days after transplanting). The entire experiment was repeated three times; thus, with five replicates per ex- periment, there were 15 ratings for each treatment.

Statistical analyses. For both the pepper experiment and the butternut squash experiment, results were pooled for statistical analysis across all three repetitions of the respective experiment. Control treatments which did not receive $P$. capsici (i.e., no M. albus + no P. capsici, only $M$. albus at $3.75 \mathrm{~g} /$ liter, only $M$. albus at 1.9 $\mathrm{g} /$ liter, and only $M$. albus at $0.55 \mathrm{~g} /$ liter) were not included in the statistical analysis, so that there were a total of five treatments and either five pepper cultivars or a single butternut squash cultivar in each analysis. All data were analyzed using SAS (version 9.1.3; SAS Institute, Cary, NC).

Data from the pepper experiment was analyzed using a nonparametric test for two-way factorial experiments, described by Shah and Madden (22). It was followed by calculation of the relative treatment effects and their $95 \%$ confidence intervals using the LD_CI macro written by Brunner et al. (3). The relative treatment effects are estimated using the ranks of the observations and are directly related to the values of the observations, so that smaller relative treatment effects for a treatment indicate smaller values for the observations (disease severity ratings) in that treatment (3). Relative treatment effects always have values between 0 and 1 , and the disease severities on two treatment-cultivar combinations can be said to be significantly different from each other if the $95 \%$ confidence intervals of the relative treatment effects do not overlap.

Data from the butternut squash experiment was analyzed using a Kruskal-Wallis test performed with the program 'npar1way.' Rank sums calculated with this program were then used to perform a Bonferroni-Dunn test (23).

\section{RESULTS}

Disease development on pepper and butternut squash. Disease developed rapidly in pathogen-inoculated controls. After 3 or 4 days, leaves began to wilt and water-soaked lesions were observed on the stems just above the soil line of the butternut squash and Red Knight pepper that had been treated with only $P$. capsici. Seven days after transplanting, all of these butternut squash and Red Knight pepper were rated either 4 or 5 . No phytotoxic effects of M. albus were observed on any pepper cultivar or on Waltham butternut squash.

Susceptibility of sweet pepper cultivars. As expected, there were differences in susceptibility among pepper cultivars. Paladin was the most tolerant pepper cultivar and Red Knight was the most susceptible pepper cultivar (Fig. 1; Table 1). The susceptibility of Alliance, Aristotle, and Revolution pepper was intermediate to that of Paladin and Red Knight, with Revolution being the most tolerant of the three 
intermediately tolerant cultivars (Fig. 1; Table 1).

Efficacy of $M$. albus to control $P$. capsici on sweet pepper. Results of the pepper experiment are presented as median disease severity rating, relative treatment effect, and $95 \%$ confidence interval of the relative treatment effect (Table 1 ). Although median ratings between two treatment-cultivar combinations may be the same, whether or not there is a significant difference is determined by the $95 \%$ confi-

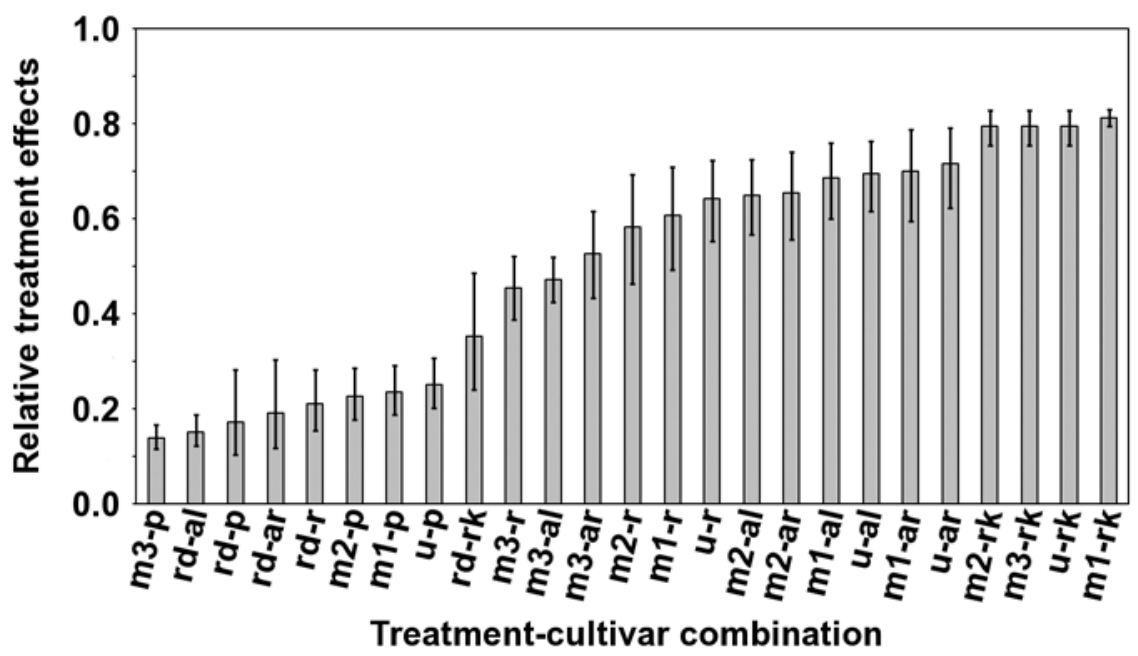

Fig. 1. Graphical representation of the relative treatment effects for each combination of treatment applied to potting mix and pepper cultivar and its effect on disease severity of Phytophthora blight on sweet pepper. Disease severity was rated on an ordinal scale from 0 (healthy plants) to 5 (dead plants), 7 days after transplanting, and data were combined from the three experiments. Error bars indicate the 95\% confidence intervals of the relative treatment effects. The first two letters and numbers indicate the soil treatment $(\mathrm{m} 1, \mathrm{~m} 2$, and $\mathrm{m} 3=$ Muscodor albus at 0.55 .1 .9 , and $3.75 \mathrm{~g} /$ liter; $\mathrm{u}=$ Phytophthora capsici only, and $\mathrm{rd}=$ mefenoxam). The second one or two letters indicate the pepper cultivar $(\mathrm{p}=$ Paladin, al = Alliance, $\mathrm{r}=$ Revolution, $\mathrm{ar}=$ Aristotle, and $\mathrm{rk}=$ Red Knight $)$.

Table 1. Median disease rating, mean rank, relative treatment effect $\left(\hat{\mathrm{p}}_{i j}\right)$ and $95 \%$ confidence interval (CI) of the relative treatment effect for combinations of soil treatment and sweet pepper cultivar ${ }^{\mathrm{X}}$

\begin{tabular}{|c|c|c|c|c|}
\hline Cultivar-treatment combination & Median $^{y}$ & Mean rank ${ }^{\mathrm{z}}$ & $\hat{\mathbf{p}}_{i j}$ & $95 \%$ CI for $\hat{\mathbf{p}}_{i j}$ \\
\hline \multicolumn{5}{|l|}{ Alliance } \\
\hline Muscodor albus $3.75 \mathrm{~g} / \mathrm{liter}$ & 4.0 & 202.5 & 0.471 & $(0.425,0.519)$ \\
\hline M. albus $1.9 \mathrm{~g} /$ liter & 4.0 & 202.5 & 0.649 & $(0.566,0.724)$ \\
\hline M. albus $0.55 \mathrm{~g} / \mathrm{liter}$ & 5.0 & 305.0 & 0.686 & $(0.600,0.760)$ \\
\hline Phytophthora capsici only & 5.0 & 305.0 & 0.694 & $(0.615,0.763)$ \\
\hline Mefenoxam & 0.0 & 48.0 & 0.151 & $(0.122,0.187)$ \\
\hline \multicolumn{5}{|l|}{ Aristotle } \\
\hline M. albus $3.75 \mathrm{~g} /$ liter & 4.0 & 202.5 & 0.525 & $(0.434,0.615)$ \\
\hline M. albus $1.9 \mathrm{~g} / \mathrm{liter}$ & 5.0 & 305.0 & 0.654 & $(0.556,0.739)$ \\
\hline M. albus $0.55 \mathrm{~g} / \mathrm{liter}$ & 5.0 & 305.0 & 0.700 & $(0.594,0.787)$ \\
\hline P. capsici only & 5.0 & 305.0 & 0.715 & $(0.623,0.792)$ \\
\hline Mefenoxam & 0.0 & 48.0 & 0.191 & $(0.118,0.303)$ \\
\hline \multicolumn{5}{|l|}{ Paladin } \\
\hline M. albus $3.75 \mathrm{~g} /$ liter & 0.0 & 48.0 & 0.139 & $(0.116,0.167)$ \\
\hline M. albus $1.9 \mathrm{~g} / \mathrm{liter}$ & 0.0 & 48.0 & 0.226 & $(0.176,0.286)$ \\
\hline M. albus $0.55 \mathrm{~g} /$ liter & 1.0 & 116.5 & 0.235 & $(0.187,0.292)$ \\
\hline P. capsici only & 1.0 & 116.5 & 0.250 & $(0.201,0.307)$ \\
\hline Mefenoxam & 0.0 & 48.0 & 0.172 & $(0.103,0.282)$ \\
\hline \multicolumn{5}{|l|}{ Red Knight } \\
\hline M. albus $3.75 \mathrm{~g} / \mathrm{liter}$ & 5.0 & 305.0 & 0.794 & $(0.753,0.829)$ \\
\hline M. albus $1.9 \mathrm{~g} / \mathrm{liter}$ & 5.0 & 305.0 & 0.794 & $(0.753,0.829)$ \\
\hline M. albus $0.55 \mathrm{~g} / \mathrm{liter}$ & 5.0 & 305.0 & 0.812 & $(0.794,0.829)$ \\
\hline P. capsici only & 5.0 & 305.0 & 0.794 & $(0.753,0.829)$ \\
\hline Mefenoxam & 1.0 & 116.5 & 0.352 & $(0.240,0.485)$ \\
\hline \multicolumn{5}{|l|}{ Revolution } \\
\hline M. albus $3.75 \mathrm{~g} /$ liter & 3.0 & 155.0 & 0.454 & $(0.388,0.521)$ \\
\hline M. albus $1.9 \mathrm{~g} / \mathrm{liter}$ & 4.0 & 202.5 & 0.583 & $(0.462,0.693)$ \\
\hline M. albus $0.55 \mathrm{~g} / \mathrm{liter}$ & 4.0 & 202.5 & 0.607 & $(0.493,0.709)$ \\
\hline P. capsici only & 4.0 & 202.5 & 0.642 & $(0.553,0.722)$ \\
\hline Mefenoxam & 0.0 & 48.0 & 0.210 & $(0.154,0.282)$ \\
\hline
\end{tabular}

${ }^{\mathrm{x}}$ Rating data taken 7 days after transplanting were combined from the three experiments.

${ }^{y}$ Disease severity was rated on an ordinal scale from 0 (healthy plants) to 5 (dead plants).

${ }^{\mathrm{z}}$ Mean rank is the average of the rank scores assigned to all replicates of each treatment-cultivar combination. Thus, treatment-cultivar combinations with smaller mean ranks received lower disease severity ratings.

dence interval of the relative treatment effect. To more easily visualize significant differences, relative treatment effects and their $95 \%$ confidence intervals are graphed in Figure 1.

Mefenoxam and the highest rate of $M$. albus, but not the other rates, significantly decreased disease severity on Alliance, Aristotle, Paladin, and Revolution pepper. Although both mefenoxam and the highest rate of $M$. albus significantly reduced disease severity compared with the pathogenonly control, mefenoxam provided better control than M. albus. There were no significant differences in disease severity between Revolution pepper and either Alliance or Aristotle pepper when these cultivars were treated with the highest rate of M. albus. Only treatment with mefenoxam significantly reduced disease severity on Red Knight pepper (Fig. 1; Table 1). Overall, only the use of Paladin (in combination with any treatment applied to the soil) or other sweet pepper cultivars treated with mefenoxam resulted in median disease ratings of 0 or 1 (Table 1 ).

Interaction between pepper cultivar and treatment of soil on disease severity. Both sweet pepper cultivar and soil treatment had significant effects on disease severity ratings $(P<0.0001$; Table 2$)$. The interaction between soil treatment and cultivar was also significant $(P<0.0001$; Fig. 2; Table 2). Thus, disease severity on each pepper cultivar varied with the treatment applied to the soil, but disease severity did not vary in the same way across all cultivars.

Efficacy of $M$. albus to control $P$. capsici on butternut squash. The butternut squash cv. Waltham was highly susceptible to $P$. capsici (Table 3). Treatment with mefenoxam significantly reduced disease severity on butternut squash compared with treatment with either $P$. capsici alone or $P$. capsici with any rate of $M$. albus (Table 3). Mefenoxam was the only treatment that prevented rapid plant death (Table 3).

\section{DISCUSSION}

P. capsici continues to be a serious disease of pepper and cucurbits in temperate climates, in spite of the use of crop rotation and fungicides (8). Previous studies have documented the successful control of soilborne $(2,16)$ and postharvest $(6,15$, 17,20) diseases using $M$. albus. Mefenoxam currently provides good control of Phytophthora blight in fields where $P$. capsici is still sensitive to the fungicide but mefenoxam-insensitive isolates are prevalent in many fields (8), including both Long Island and some areas of upstate New York (9; unpublished data). There are, however, still some locations in upstate New York that have mefenoxamsensitive populations (unpublished data). Because insensitivity to mefenoxam can develop in populations of $P$. capsici that 
are repeatedly exposed to the fungicide, alternative control methods for Phytophthora blight are needed, whether chemical, biological, or cultural (8).

Under the conditions of this study, the previously described complete biofumigation effects of $M$. albus on $P$. capsici were not observed. Addition of the highest rate of $M$. albus did reduce disease severity in four of the five pepper cultivars tested; however, the level of disease was still very high in all cultivars except Paladin. The potting mix in the Mercier and Manker (16) study was inoculated with $P$. capsici at a much higher rate (inoculum:potting mix ratio of $1: 1$, compared with $1: 4$ in this study); thus, the level of inoculum does not account for the difference observed between these two studies. A likely explanation for the results obtained by Mercier and Manker is the rate of M. albus used to fumigate the potting mix. Soil was inoculated with $M$. albus (grown on rye grain, as in this experiment) at $25 \mathrm{~g} /$ liter of potting mix, which is a significantly higher rate than was used in this study (the rate suggested by the manufacturer). Also, different strains of the pathogen were used in

Table 2. Results of nonparametric analysis of variance for the effects of treatment and cultivar on disease severity caused by Phytophthora capsici on sweet pepper ${ }^{y}$

\begin{tabular}{lcccc}
\hline & \multicolumn{4}{c}{ Analysis of variance-type statistics $^{\mathbf{z}}$} \\
\cline { 2 - 5 } Effect & $\mathbf{d f}_{\mathbf{N}}$ & $\mathbf{d f}_{\mathbf{D}}$ & $\boldsymbol{F}$ & $\boldsymbol{P}_{\text {value }}$ \\
\hline Treatment & 3.81 & 226 & 90.3 & $<0.0001$ \\
Cultivar & 3.57 & 226 & 107.25 & $<0.0001$ \\
Treatment $\times$ cultivar & 11.8 & 226 & 4.97 & $<0.0001$ \\
\hline
\end{tabular}

${ }^{\mathrm{y}}$ Treatments were Muscodor albus at $0.55,1.9$, and $3.75 \mathrm{~g} /$ liter; $P$. capsici only, and mefenoxam. Cultivars were Paladin, Alliance, Revolution, Aristotle, and Red Knight. Disease severity was rated on an ordinal scale from 0 (healthy plants) to 5 (dead plants), 7 days after transplanting. Data were combined from the three experiments.

${ }^{\mathrm{z}}$ Numerator and denominator degrees of freedom $=\mathrm{df}_{\mathrm{N}}$ and $\mathrm{df}_{\mathrm{D}}$, respectively.

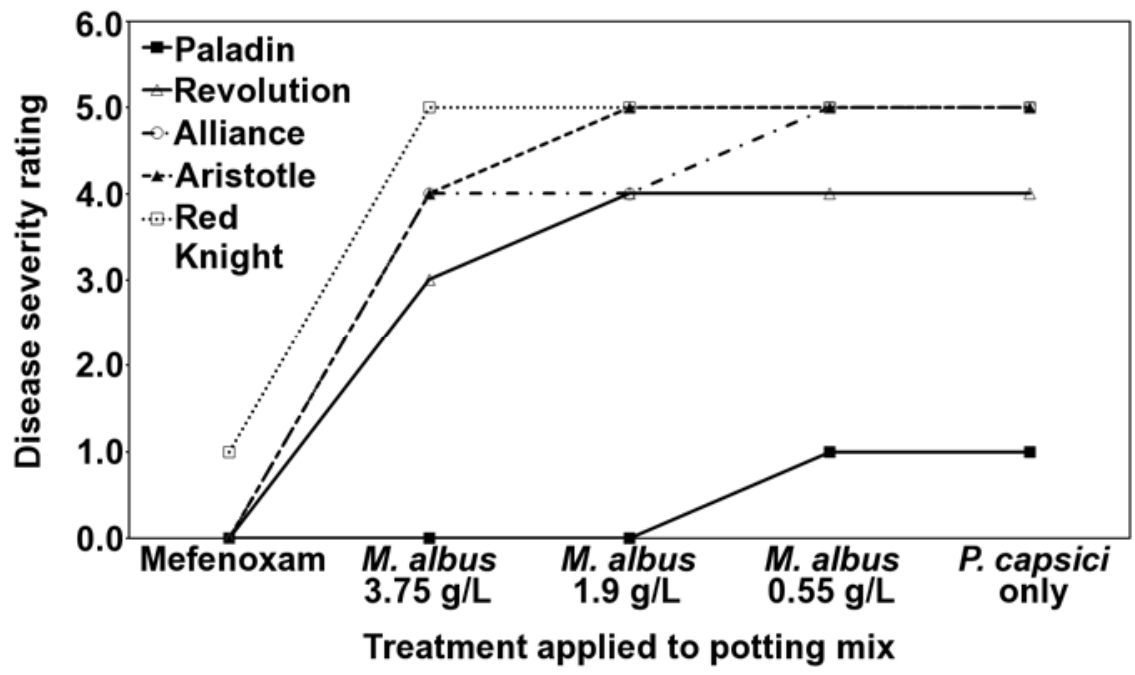

Fig. 2. Median disease severity caused by Phytophthora blight on five pepper cultivars across five treatments applied to potting mix. All potting mix was infested with Phytophthora capsici and treated with mefenoxam, three rates of Muscodor albus, or no additional treatment. Disease severity was rated on an ordinal scale from 0 (healthy plants) to 5 (dead plants), 7 days after transplanting, and data were combined from the three experiments. The fact that the lines representing the different cultivars do not remain equidistant across the soil treatments indicates that an interaction has likely occurred, and this is confirmed by the analysis shown in Table 2 (23). the most tolerant of the cultivars included in this study. However, it has been noted that this tolerance can be overcome in the field under conducive environmental conditions (8). Because the highest rate of $M$. albus used in this study significantly reduced disease severity on all pepper cultivars except Red Knight, it is possible that a high rate of $M$. albus could effectively limit losses of tolerant pepper cultivars under high disease pressure. In this study, Revolution was more susceptible than Paladin but not as susceptible as Red Knight pepper, which is consistent with a previous report of some tolerance of this cultivar to $P$. capsici in the field $(40 \%$ incidence after artificial inoculation; 13).

There have been mixed reports of the tolerance level of pepper cv. Aristotle to Phytophthora blight, ranging from $20 \%$ mortality (5) to $91 \%$ mortality (14) in field trials. One study reported Alliance pepper to be fairly susceptible to Phytophthora blight (more than 60\% incidence after artificial field inoculation; 13). Under the conditions of this study, both Aristotle and Alliance pepper responded similarly to the applied soil treatments and, together with Revolution pepper, were classified as "less tolerant," because they were slightly less susceptible than Red Knight pepper. The differences in reported levels of tolerance on each pepper cultivar over multiple studies may be due to different experimental conditions and the use of different isolates of P. capsici.

Red Knight is a highly susceptible pepper cultivar (14) and similar results were seen in this study, where Red Knight was the most susceptible cultivar tested. Application of $M$. albus did not reduce disease severity on Red Knight and, in sharp contrast to Paladin, treatment with mefenoxam produced a substantial reduction in disease severity on Red Knight.

As applied in this study, M. albus did not control $P$. capsici on butternut squash. All plants exposed to $P$. capsici (except those treated with mefenoxam) died rapidly. Although no Phytophthora blight

Table 3. Effect of soil treatments on median disease severity caused by Phytophthora capsici on butternut squash ${ }^{y}$

\begin{tabular}{lc}
\hline Treatment & $\begin{array}{c}\text { Disease } \\
\text { severity }^{\mathbf{z}}\end{array}$ \\
\hline Muscodor albus $3.75 \mathrm{~g} /$ liter & $4.5 \mathrm{a}$ \\
M. albus $1.9 \mathrm{~g} / \mathrm{liter}$ & $4.0 \mathrm{a}$ \\
M. albus $0.55 \mathrm{~g} /$ liter & $5.0 \mathrm{a}$ \\
P. capsici only & $5.0 \mathrm{a}$ \\
Mefenoxam & $0.0 \mathrm{~b}$ \\
\hline y Cv. Waltham was used and disease severity \\
was rated on an ordinal scale from 0 (healthy \\
plants) to 5 (dead plants), 7 days after trans- \\
planting. Rating data were combined from the \\
three experiments. \\
z Medians followed by the same number are not \\
significantly different from each other by a \\
Kruskal-Wallis test followed by a Dunn's test \\
at $P=0.05$.
\end{tabular}


resistance is currently available in butternut squash, research is in progress to identify sources of resistance to $P$. capsici $(10,18)$. The results of the present study indicate that $M$. albus does not control $P$. capsici on highly susceptible cucurbit hosts.

As applied in this study, M. albus did not provide complete biofumigation of $P$. capsici-infested soil; however, at 3.75 $\mathrm{g} /$ liter, it did significantly reduce disease severity on partially tolerant pepper cultivars. Therefore, although M. albus will likely not protect highly susceptible host crops from infection with $P$. capsici, it is possible that $M$. albus could be used in combination with host plant tolerance to reduce severity of Phytophthora blight. Additional studies are needed to determine if the use of M. albus in conjunction with resistant cultivars could be part of an effective integrated pest management program.

\section{ACKNOWLEDGMENTS}

This study was funded in part by a grant from the New York State Department of Agriculture and Markets. We thank D. Shah for statistical advice; B. Highland and Agraquest, Inc. for providing materials and partial support; and H. Lange, M. B. Herman, A. Cobb, and K. Kohl for help in setting up greenhouse trials.

\section{LITERATURE CITED}

1. Babadoost, M., and Islam, S. Z. 2002. Bell peppers resistant to Phytophthora blight. (Abstr.) Phytopathology 92:S5.

2. Baysal, F., Mera, J. R., and Miller, S. A. 2007. Effects of Muscodor, Serenade and conventional fungicides on Rhizoctonia root and hypocotyl rot and clubroot of radish. (Abstr.). Phytopathology 97:S9.

3. Brunner, E., Domhof, S., and Langer, F. 2002. Nonparametric Analysis of Longitudinal Data in Factorial Experiments. John Wiley \& Sons, New York.

4. Davidson, C. R., Carroll, R. B., Evan, T. A., and Mulrooney, R. P. 2002. First report of Phytophthora capsici infecting lima bean (Phaseo- lus lunatis) in the mid-Atlantic region. Plant Dis. 86:1049.

5. Driver, J. G., and Louws, F. J. 2003. Management of Phytophthora crown and root rot in peppers. (Abstr.) Phytopathology 93:S22.

6. Gabler, F. M., Fassel, R., Mercier, J., and Smilanick, J. L. 2006. Influence of temperature, inoculation interval, and dosage on biofumigation with Muscodor albus to control postharvest gray mold on grapes. Plant Dis. 90(8):1019-1025.

7. Gevens, A. J., Donahoo, R. S., Lamour, K. H., and Hausbeck, M. K. 2008. Characterization of Phytophthora capsici causing foliar and pod blight of snap beans in Michigan. Plant Dis. 92:201-209.

8. Hausbeck, M. K., and Lamour, K. H. 2004. Phytophthora capsici on vegetable crops: research progress and management challenges. Plant Dis. 88(12):1292-1303.

9. Johnston, S. A., Kline, W. L., Fogg, M. L., and Zimmerman, M. D. 2002. Varietal resistance evaluation for control of Phytophthora blight of pepper. (Abstr.) Phytopathology 92:S40

10. Kabelka, E., Padley, L., Roberts, P., Ramos, L., Martinez, M., and Klassen, W. 2007. Resistance to Phytophthora capsici within winter squash (Cucurbita moschata) derived from a wild Cucurbita species. Hortscience 42(4): 1014-1014.

11. Lamour, K. H., and Hausbeck, M. K. 2000. Mefenoxam insensitivity and the sexual stage of Phytophthora capsici in Michigan cucurbit fields. Phytopathology 90(4):396-400.

12. Leonian, L. H. 1922. Stem and fruit blight of peppers caused by Phytophthora capsici sp. nov. Phytopathology 12:401-408.

13. Louws, F. J., and Driver, J. G. 2007. Evaluation of pepper lines for resistance to Phytophthora crown and root rot, 2006. In: Plant Disease Management Reports (online). Report 1:V118. DOI:10.1094/PDMR01 The American Phytopathological Society, St. Paul, MN.

14. McGrath, M. T., and Davey, J. F. 2007. Efficacy of fungicides for control of Phytophthora blight in pepper on crown rot tolerant and susceptible cultivars, 2006. In: Plant Disease Management Reports (online). Report 1:V131. DOI:10.1094/PDMR01 The American Phytopathological Society, St. Paul, MN.

15. Mercier, J., and Jimenez, J. I. 2004. Control of fungal decay of apples and peaches by the biofumigant fungus Muscodor albus. Postharvest Biol. Technol. 31(1):1-8.

16. Mercier, J., and Manker, D. C. 2005. Biocontrol of soil-borne diseases and plant growth enhancement in greenhouse soilless mix by the volatile-producing fungus Muscodor albus. Crop Prot. 24(4):355-362.

17. Mercier, J., and Smilanick, J. L. 2005. Control of green mold and sour rot of stored lemon by biofumigation with Muscodor albus. Biol. Control 32 (3):401-407.

18. Padley, L., Roberts, P., and Kabelka, E. 2007. Screening Cucurbita pepo for resistance to Phytophthora capsici. Hortscience 42(4):10141014.

19. Ristaino, J. B., Duniway, J. M., and Marois, J. J. 1988. Influence of frequency and duration of furrow irrigation on the development of Phytophthora root rot and yield in processing tomatoes. Phytopathology 78:1701-1706.

20. Schnabel, G., and Mercier, J. 2006. Use of a Muscodor albus pad delivery system for the management of brown rot of peach in shipping cartons. Postharvest Biol. Technol. 42(1):121123.

21. Schotsmans, W. C., Braun, G., DeLong, J. M., and Prange, R. K. 2008. Temperature and controlled atmosphere effects on efficacy of $M u s$ codor albus as a biofumigant. Biol. Control 44(1):101-110.

22. Shah, D. A., and Madden, L. V. 2004. Nonparametric analysis of ordinal data in designed factorial experiments. Phytopathology 94(1):3343.

23. Sheskin, D. J. 1996. Handbook of Parametric and Nonparametric Statistical Procedures. CRC Press, Boca Raton, FL.

24. Silvar, C., Merino, F., and Diaz, J. 2006. Diversity of Phytophthora capsici in northwest Spain: analysis of virulence, metalaxyl response, and molecular characterization. Plant Dis. 90(9):1135-1142.

25. Stinson, A. M., Zidack, N. K., Strobel, G. A., and Jacobsen, B. J. 2003. Mycofumigation with Muscodor albus and Muscodor roseus for control of seedling diseases of sugar beet and Verticillium wilt of eggplant. Plant Dis. 87(11):1349-1354.

26. Strobel, G. 2006. Muscodor albus and its biological promise. J. Ind. Microbiol. Biotechnol. 33(7):514-522. 